\title{
Article \\ Qualitative Stakeholder Analysis for a Swedish Regional
Biogas Development: A Thematic Network Approach
}

Komalsingh Rambaree ${ }^{1, *(\mathbb{D}}$, Agneta Sundström ${ }^{2}$, Zhao Wang ${ }^{3}$ and Sandra Ann Ingela Wright ${ }^{4}$

1 Department of Social Work and Criminology, University of Gävle, 80176 Gävle, Sweden

2 Department of Business and Economic Studies, University of Gävle, 80176 Gävle, Sweden; agneta.sundstrom@hig.se

3 Department of Building Engineering, Energy Systems and Sustainability Science, University of Gävle, 80176 Gävle, Sweden; zhao.wang@hig.se

4 Department of Electrical Engineering, Mathematics and Natural Sciences, University of Gävle, 80176 Gävle, Sweden; sandra.wright@hig.se

* Correspondence: kolsie@hig.se; Tel.: +46-(0)-702226517; Fax: +46-(0)-26-648686

Citation: Rambaree, K.; Sundström,

A.; Wang, Z.; Wright, S.A.I.

Qualitative Stakeholder Analysis for a Swedish Regional Biogas Development: A Thematic Network Approach. Sustainability 2021, 13, 8003. https://doi.org/10.3390/ su13148003

Academic Editor: Dorota Kuchta

Received: 27 May 2021

Accepted: 9 July 2021

Published: 17 July 2021

Publisher's Note: MDPI stays neutral with regard to jurisdictional claims in published maps and institutional affiliations.

Copyright: (c) 2021 by the authors. Licensee MDPI, Basel, Switzerland. This article is an open access article distributed under the terms and conditions of the Creative Commons Attribution (CC BY) license (https:// creativecommons.org/licenses/by/ $4.0 /)$.

\begin{abstract}
The creation of pathways toward a societal transition to clean energy requires the engagement of multiple stakeholders with different and sometimes conflicting interests. In this connection, stakeholder analysis (SA) offers a technique for identifying, assessing and structuring different needs, interests and concerns related to different stakeholders within the context of sustainability. This article aims to present the findings from a qualitative stakeholder analysis (QSA) by using a thematic network approach (TNA), with the help of the ATLAS.ti software. It focuses on Project X, which was aimed at engaging multiple stakeholders and creating favorable conditions for small and medium-sized companies in a region situated in the central part of Sweden, with the potential to start biogas production. In this work, the findings and discussions of the QSA using TNA are structured by using the political, economic, social, technological, environmental and legal (PESTEL) themes of the model. The present study concludes that for the small-scale biogas industry to successfully develop an understanding of the possibilities of the biogas value chain, it is necessary to have analyzed the nature of the main themes by which various stakeholders relate to biogas production and envision their contribution to creating a sustainable society. Herein, we demonstrate that QSA by a TNA, combined with the application of a PESTEL model, are valuable analytical tools in sustainable project management. The lessons from Project $X$ can be applied to other local biogas initiatives, as many identified threats and opportunities are shared by others.
\end{abstract}

Keywords: biogas; energy; PESTEL; qualitative stakeholder analysis; thematic network approach

\section{Introduction}

Sustainability is a multi-dimensional and multi-faceted discipline (economic, ecological, social, etc.), which renders the transition to the circular economy complex. From an ecological perspective, sustainability is often described as a moral imperative to preserve the bio-physical environment and support biodiversity; its realization calls for changes in human attitudes, behavior and practices [1]. In this sense, the development of areas that are conducive to a transition to sustainability, such as regional biogas production, requires careful consideration of the well-being of humans and the planet [2]. In this endeavor, the transition to sustainable development depends on the attitudes of a wide range of stakeholders in society. The implementation of sustainability principles (ecological, economic, and social pillars) is concerned with how stakeholders succeed in applying knowledge, skills and operate projects to ensure value and advantages for all in the society [3-5]. It is argued that the application of sustainability principles in stakeholder management can contribute to long-term societal development, through the creation of value, business agility, and operational and business excellence [6]. In essence, sustainable stakeholder 
management calls for commitment at many levels, and the satisfaction of all affected and involved stakeholders [5].

Stakeholders, represented by individuals and groups that have an interest in sustainability development activities, play a central role in the success of this transition [7]. Engaging multiple stakeholders with different and sometimes conflicting needs and interests can be very challenging in sustainable development projects, such as those creating pathways towards a clean energy transition. This case study explores these issues in the context of regional biogas development. It focuses on stakeholder influence on biogas production, by offering a fossil-free energy alternative during the transition to a circular economy. To promote that process successfully, it is necessary that prominent stakeholders support the effort of developing biogas production, in the quest for a fossil-free society.

Most municipalities in the central region of Sweden are striving to move towards a more circular economy; they are already source-separating food waste, which is an excellent substrate for biogas production. However, today, this region of Sweden does not have the capacity to meet the amount of collected food waste, and other types of organic substrates that are suitable for biogas production. Consequently, some of the collected organic waste is transported to facilities that are far outside the region. This leads to a loss in both local energy production in the form of biogas, as well as in plant nutrients in the form of bio-fertilizer, to other regions in Sweden. As a matter of fact, even if regional biogas development seems to follow the national trend, the actual production of both raw and upgraded biogas remained at a considerably lower level during 2008-2019, as compared to the national average [8]. A transition to local biogas production in the region would therefore have twice the effect on mitigating climate change, through diminished emissions from road transport of wastes, and through the replacement of fossil fuels by a regionally produced green biofuel, a renewable resource. Some owners of small businesses in the region who work with technical support look forward to regional biogas development. Some farms in the region display an interest and willingness to convert agricultural residues to biogas and bio-fertilizer on site, despite prospects of high investment costs and low profitability. In addition, some municipalities in the region consider local biogas production as one of many alternative ways to increase the employment rate.

Previous biogas research has been aimed at analyzing technical and productionoriented solutions [9], transport-related issues and policies [10-12] and developing success factors by using innovative business models $[13,14]$. So far, few studies have investigated the sustainability factors that stakeholders perceive to have potential, and, hence, investigating their importance in influencing and developing the inclusion of biogas as a fossil-free energy solution. To fill this gap, this study suggests that the systematic approach of undertaking stakeholder analysis (SA) is essential to the success of local transition to biogas.

Commonly, SA is applied for identifying, assessing and structuring the different needs, interests, issues and concerns of different stakeholders, and as such is instrumental in initiating and achieving transitions to sustainability. As a method, SA has developed into a tool, or set of tools, for a variety of different purposes and approaches in the fields of policy, management and sustainability implementation [15]. Moreover, most stakeholder studies apply Social Network Analysis (SNA) to evaluate how different stakeholders relate to each other in a specific area of interest. For example, Henriksen focused on stakeholder networks, governance and positioning of sustainability standards [16]. In this way, most SNA approaches start from, and direct attention towards, an actor perspective, where the stakeholders themselves are at the center of the analysis. Nevertheless, there are SNA studies that advocate for a mixed-method analysis, to gain a deeper understanding of the qualitative aspects of a certain phenomenon [17]. However, these are few and lack the support of analytical tools, such as ATLAS.ti software, for the treatment of qualitative data. For example, some previous studies have looked at sustainability themes on concerns and ecologic, economic and social issues that are of a qualitative nature [18,19]. However, these do not use qualitative stakeholder analysis (QSA), supported by thematic network analysis 
(TNA) through PESTEL (political, economic, social, technological, environmental and legal dimensions), as suggested in the present study. A PESTEL analysis is an analytical tool that originates from market analysis and management, utilized as a strategic framework for understanding the external factors that may affect a business or an operation. In this study, a PESTEL analysis was used to identify the external influences on biogas development from the point of view of stakeholders, and subsequently examine and determine the influential factors in terms of political, economic, social, technological, environmental and legal considerations.

To our knowledge, most users of QSA focus on how the software ATLAS.ti (used herein) can be applied [20]. In particular, limited attention has been given to the manner by which this software can be useful as a TNA in the analysis, when applying a PESTEL perspective to the role of biogas in sustainability transitions. Furthermore, by using ATLAS.ti, this study presents and thematically applies QSA by focusing on sustainability themes from a PESTEL (multidisciplinary) perspective. This approach is also contrasted to previous TNA studies, as it primarily focuses on central sustainability themes as discussed by the stakeholders, where the actors as participants are secondary to consideration.

The aim of the present study was to investigate the perceptions of stakeholders regarding the sustainability factors of PESTEL, and to determine how these perceptions contribute to the development of biogas as a fossil-free energy solution through a QSA using TNA. This study answers a central research question: How can a QSA that uses a TNA through PESTEL be undertaken in order to identify and analyze opportunities and threats as perceived by stakeholders of a project, for the successful development of local biogas production in a region?

\section{Literature Review: Theoretical and Conceptual}

\subsection{Stakeholder Theory}

Stakeholder theory originates from strategic management discourses, with the basic tenet that stakeholders are critical in business management as they affect the long-term strategic goals of the business (or project) [21]. However, there are different opinions expressed in different business management discourses, as to who is regarded as a stakeholder. This discussion goes back to Freeman's work in 1984 on who can be counted as a stakeholder, and to whom managers should pay attention [22]. According to Freeman's definition, a stakeholder 'is any group or individual that can affect or is affected by the achievement of a corporation's purpose' [23] (p. 49), which means that it is difficult to define the specific stakeholder that contributes to the creation of a shared value. Mitchell et al. argue that stakeholders are only those with legitimized claims on the business [24]. In their developed model of stakeholder theory, they define stakeholders as the groups that managers perceive to have three important attributes: power, legitimacy and urgency. Therefore, the individuals and groups possessing these attributes are considered as those that require significant attention from business managers [21]. These attributes are interrelated and merge into different typologies of stakeholders, with different expectations from businesses. Some typologies have used simple dichotomous groupings, such as primary vs. secondary, wide vs. narrow, active vs. passive, while others have used more elaborate systematizations with seven to ten typologies of stakeholders [25]. In most typologies, only those stakeholders who possess all three attributes-power, legitimacy and urgency-are considered the 'definitive stakeholders', which are those with the right to make claims on business [24] (p. 873). This implies that managers have to identify stakeholder attributes, and prioritize the demands of various stakeholder groups, in which the interest of the business comes first [26].

Stakeholder theory is one of the most frequently used approaches in business management and sustainability research [27]. The theory has its roots in systems thinking, where an organization and its management are analytically and practically linked to broader social systems, within the field of operation in the organization. Antecedents, such as Chester I. Barnard's classic work-The Function of the Executive-laid the foundation for 
seeing organizations as the result of structures and processes that arise between actors as part of social systems [28] (pp. 215-285). He developed the 'theory of coöperation', which is essential to any organization, arguing that cooperation and organization are normally separated and treated as two different entities. He claims that organizations consist of the social processes of humans, which are not solely governed by formal requirements. These are the result of actions that are influenced by the social activities of others, which the organization typically is not aware of. These actions are undertaken by the stakeholders in which the organization depends on in their cooperative social system. On the other hand, Rhenman and Stymne concentrated on the strategic need for organizations to manage stakeholders as a part of the management's decision making [29]. Furthermore, they claimed that the goals of the organization are equal to those of the stakeholders, and, hence, the task of management is to govern according to the shared stakeholder value principle. Their stakeholder model, developed to provide structural support for management, was designed as help to identify how they could steer the organization toward engaging in value-based and shared goals. However, this early theoretical model, proposed as a means of solving classic strategic management problems that have centered on value chain financial values, has since been severely criticized [30].

During the past decade, stakeholder theory by Freeman et al. has received due attention, arguing that stakeholders are at the center of strategic management thinking [26,31]. Stakeholder theory was largely influenced by the idea that organizations need to be managed with due consideration to all stakeholders, not only with the interests of shareholders in mind [32]. Indeed, no organization can function in isolation without any relationship to its immediate societal environment or stakeholders. Within the field of strategic management, Freeman pioneered the extension of corporate responsiveness with the inclusion of all individuals and groups in society that have a stake in the organization. The argument was that the unit for analysis needs to be changed to a relational view of business, which means that economics develops through social relations and interactions. Stakeholders have a social responsibility to those who affect, or are affected by, the achievements of an organization, where the intersection between different stakeholders forms the basis for effective and sustainable stakeholder management [32]. During crises, stakeholder management can create opportunities for better insights into project management, which would not otherwise be possible. Hence, it is important to have a well-planned SA in any sustainable project management.

\subsection{Stakeholder Analysis}

SA is viewed as a process that facilitates decision making in areas of development, based on the study of aspects related to social, economic and environmental phenomena, and their respective effects on individuals, groups and organizations [33]. It helps developers avoid failures by having a sound understanding of the dynamics that influence the policies and activities of the project. It also promotes a participatory approach in decision making and the implementation of activities that promote sustainable project management. In some cases, $\mathrm{SA}$ is used as a platform for sharing knowledge, facilitating negotiating and promoting collaboration among stakeholders [33] Although SA originates from business sciences, it has now become an integral part of other disciplines. Today, stakeholder theory (ST) and SA are an essential part of participatory and multidisciplinary approaches through understanding and resolving sustainability challenges from a stakeholder perspective [34]

An SA that focuses solely on social interaction for developing economics, shared value becomes problematic in a multidisciplinary approach, in which the end goal is to result in integrated perspective of sustainability transformation or research. In addition, the predominance of managerial interests in the research agenda of stakeholder theory, rather than those of the stakeholder, is problematic, as several crucial factors in sustainable business management are ignored [35]. Contemporary stakeholder theory research therefore questions the historical assumption that a pursuit of financial gain is the primary management concern. In fact, SA requires the analysis of ethical, ecological, political and sociological 
perspectives on the links/relationships between organizations and society $[27,36]$. Thus, such complex interactions between different dimensions require a balance between the benefits and other consequences of economic activities with adequate knowledge and understanding of other factors, such as the social, economic and environmental factors, which form part of a broader SA framework [37]. In this sense, stakeholder theory is believed to be enhanced through elements of methodological guidance from broader approaches, such as those based on social systems theory, that bring the descriptive, normative and instrumental together $[36,38,39]$. According to social systems theory, business management is embedded in a complex mesh of interactions between different units (stakeholders) within different systems. The network approach to SA considers stakeholders not as autonomous units, but rather as parts of a whole system, where the interactions between the units are assumed to be strongly related to achieve sustainable business management [40].

To increase the understanding of how complex stakeholder relationships develop, research has often applied analytical techniques that make it easier to identify the factors of greatest importance in the development of a network. Some of these are presented in the next section.

\subsection{Social Network Analysis, SNA}

Studies that analyze stakeholder relationships and interactions to other actors usually apply the principles that exist in SNA, that are based on social systems theory. According to Scott, SNA is a method that bridges the gap between theory and practice [41]. Like the stakeholder antecedents, he assumes that organizations are the result of social interactions. Individuals' relationships can be analyzed in a systematic way by social networks, where different SNA techniques are used to measure the structure of these, in terms such as reciprocity, density, distance, centrality, cliques and position. In sustainability research, Henriksen has applied SNA to measure a global network of biofuel sustainability as standard setters [16]. Zhou et al. have conducted bibliometric and SNA in civil engineering sustainability research, which shows that it can be used to study relationships between variables other than human relationships [42]. As the majority of research applies a quantitative SNA approach, qualitative analysis has gradually been added to gain a deeper understanding of the unique nature of webs in the SNA results. For example, Luthe and Wyss apply SNA when they focus on resilience from a tourist supply chain perspective, which is later complemented by interviews and workshops [43]. This means that SNA can provide interesting results. However, in order to gain deeper understanding of a phenomenon, the present study shows that other qualitative analytical approaches are required, such as TNA.

\subsection{PESTEL in QSA}

In sustainability research, there is more attention on the qualitative dimension of SNA, which is a complementary quantitative approach [40], providing more exploratory and descriptive information on different phenomena within a given system that influence a certain area of study. In this context, the present article aims to introduce a QSA approach by using TNA, which is based on a PESTEL model in SA, to categorize data based on stakeholder perceptions of sustainability aspects that influence biogas development in a central region of Sweden. Often, PESTEL is analyzed through strengths, weaknesses, opportunities and threats (SWOT). However, since the complexity of biogas development is often characterized by links between stakeholders as well as policy and geodemographic influences $[10,44,45]$, the present study has focused only on two external elements: opportunities and threats.

In this study, it is assumed that stakeholders' interests and perceptions of biogas development can affect or be affected by the PESTEL aspects of sustainability. Consequently, new multidisciplinary, holistic and integrated models for stakeholder analysis, such as PESTEL, are gaining popularity in sustainability transformation initiatives and research [46-49]. A PESTEL model in QSA is a strategic, multidisciplinary framework, commonly used in 
project management to identify stakeholders and their underlying relationships across different dimensions and sectors [46]. A PESTEL model allows for the identification and analysis of the broader environment, within which a company or project operates, in order to provide a holistic picture of factors that influence successful management. Thus, one of the main advantages of using this model is that it permits a multidisciplinary analysis of factors that have an impact on a project, area of development or company [48]. As a precondition for the analyses of effective strategic management, the PESTEL model does not generally adopt a quantitative measurement approach. Rather, it focuses on factors that have a qualitative structure for in-depth analysis and evaluation [47]. In this sense, the use of a PESTEL model in QSA requires analytical skills and strategies, such as TNA, for comprehensive and in-depth analysis of rich and qualitative information. Although different PESTEL models are gaining popularity in sustainability discourses, very few studies have explored methodological techniques for analyzing qualitative data in a systematic way, while maximizing the advantages of using such an approach in SA.

Generally, PESTEL analysis has been recently applied in some energy-related studies. For instance, Achinas et al. reviewed the European biofuel industries through a sociopolitical, techno-economic, legal and environmental analysis approach, and discussed the interrelation between technological dimensions and sustainable deployment [49]. They found that one of the driving forces in the transition to biofuels is the environmental benefit, through the reduced emission of greenhouse gases, for example. European biofuel industries are driven politically by directives that have been developed by the European Commission, which advocate that each country develops its own legal framework, such as subsidies and import tariffs, in order to support national biofuel development. However, it should be pointed out that these instruments may create barriers to international trade and constrain a national market for biofuel. By also utilizing PESTEL analysis, Christodoulou and Cullinane studied the opportunities and challenges in the implementation of an energy management system at Northern European ports [47]. Therefore, this study adopts a PESTEL framework in undertaking a QSA, by using TNA as a methodology.

\section{Methodology}

This article is based on materials that were gathered during an investigatory phase of Project X (investigatory phase: December 2018-May 2019). One of the aims of Project $X$ was to investigate how multiple stakeholders (policy makers, investors, experts in various sustainability domains) work towards facilitating a transition to local biogas production for small and medium-sized enterprises (SMEs) that have the potential to start biogas production in the region studied in Sweden. In order to identify the opportunities and challenges for the small-scale biogas industry to develop successfully, data from the stakeholder analysis was collected to build a knowledge base. The attitudes of various stakeholders toward biogas production and sustainability in the region was analyzed. Stakeholder analysis was therefore executed during the investigatory phase, i.e., during Project $X$, which had the long-term goal of facilitating the establishment of sustainable and competitive biogas production for SMEs in this region of Sweden. In particular, this investigatory project, i.e., Project $X$, followed a bottom-up approach, within the framework of promoting a transition to a circular economy.

\subsection{Data Collection}

Several activities carried out during this investigatory phase sought to involve different stakeholder groups and local communities from the region, all of which could influence a transition to sustainability. Stakeholder initiatives to develop biogas production in the region have been weak in the past. Stakeholders were identified through a desk study. These stakeholders consisted of farmers, municipal waste management companies, substrate owners, policy makers, investors, labor markets and experts in various sustainability domains. The potential involvement of the stakeholders was followed up by outreach 
activities. During the project, on-site visits were made to biogas plants to observe and learn from experiences of companies with knowledge of the regional market.

Following the purpose and objectives of the research project, a questionnaire survey, discussion seminars and individual interviews were organized and carried out during February 2019 with 22 biogas-related stakeholders in the region. Data presented in this paper are therefore mainly from these 22 individual stakeholders. The questionnaire had open questions, such as: What are the conditions for increased biogas production in the region? What challenges do different actors face and how can such challenges be handled? How can biogas contribute to sustainability? Afterwards, the individuals were invited to participate in a workshop, where similar questions were raised in focus group discussions. In total there were five groups, each of about four to five participants. In addition, secondary data was also used, based on a review of the literature, to create linkages (such as associations, similarities, contradictions, etc.) to the findings. All collected data were thematically coded and analyzed by PESTEL with the use of ATLASti.9.0 software for QSA. Based on the data analysis, a model for TNA in QSA was developed.

\subsection{Thematic Approach}

Thematic approaches are commonly used in qualitative data analysis to identify patterns in seemingly random information, derived from the collected data and then organized into themes [50]. In thematic approaches, the researchers apply a technique that regroups and organizes the collected qualitative data under different central themes. A theme captures the important aspects from the stakeholders' perspective, being their interests and perceptions in relation to selected aspects of the investigation. As such, the thematically-analyzed data expresses the meanings and representations of the stakeholders in the QSA. Therefore, an in-depth QSA, which uses a thematic analysis, seeks to add value to the initial findings through central themes (the main focus) that are related to stakeholder needs, perceptions and concerns. Thematic analysis represents a creative way of identifying the salient themes in a structured manner, organized into three main types: 'basic themes' (descriptive statements about what is included in different instances of data); 'organizing themes' (clusters or groups of basic themes); and 'global themes' (theoretical claims about how the data can be understood) [51]. In this study, a thematic QSA is carried out by using the ATLAS.ti software.

\subsection{Analytical Tool-The ATLAS.ti Software}

ATLAS.ti is a computer-aided qualitative data software. This particular software is commonly used for analyzing text, image, video and geographic data. Such data are input in the software, and the process of data analysis begins with coding. Coding in qualitative data analysis is an interpretative process of assigning a summative, salient, essence-capturing and/or evocative attribute for a selected segment of data [52]. It is through the process of looking at the variations and similarities across different codes that researchers identify and organize themes that are embedded in the data [53]. Therefore, themes are a higher level of data reductions, through which similar categories of codes are assembled together. The main assumption is that from carefully and systematically examining coherent segments of the gathered empirical qualitative data through coding and then creating themes out of the codes, answers to the study's research questions can be found and a conclusion can be drawn.

The ATLAS.ti software is a graphical tool that has the ability to create networks between codes and themes and shows the interconnectivity between them, as well as identifying the source (what stakeholders, and when) of the themes [54]. The graphical illustration through the network of linkages enables different kinds of exploration, such as the relationships between themes, codes and quotations and research questions. The network platform in ATLAS.ti facilitates visualization and the exploration of answers to the set research questions in creative and systematic ways [55]. The network feature in ATLAS.ti was therefore used in generating thematic networks to identify and analyze opportunities 
and threats, as perceived by stakeholders of the Project X. Practical application of ATLAS.ti v.8.4 is supported through a freely available manual [56], which can be downloaded from https: / / atlasti.com/, (accessed on 20 May 2019).

All the materials gathered, including the literature reviewed, were used as input under a project file in ATLAS.ti. Once the project was created, several central features of ATLAS.ti, such as 'documents', 'quotations', 'codes', 'memos', 'networks' and 'links', were used for data management and analysis. The feature 'documents' was used to collect and organize all the gathered materials in various formats, such as text, multimedia, geographic imaging and location of stakeholders. The 'quotations' feature was employed for selecting segments of data identified as being relevant, in terms of the aim of Project X. Individual quotations (segments of the gathered materials) were then grouped under one or more codes. A code (which can be one or a couple of words, several particular words, or even a few sentences) is a reference given to some part of the gathered qualitative data. It facilitates the indexing, sorting and working with quotations [52]. For the SA, in the PESTEL approach, codes such as 'political', 'economic', 'social', 'technology', 'environmental and 'legal' were used. The codes were subsequently regrouped into two different elements, 'opportunities' and 'threats', which underline the goals of Project X.

The 'networks' feature in ATLAS.ti was used to generate the results of Project X. The 'networks' feature is a central workspace that allows the users to create and explore interconnections between codes, quotations and memos to create sets of related elements in a visual diagram (such as mind maps), displaying spatially clustered items [54-56]. Finally, the 'links' feature was used to create the linkages between codes, quotations and memos (by applying analytical, reflective and theoretical notes from the project management team). Different types of links (with different labels and formats) were created to depict the different kinds of relationships between the nodes.

The ATLAS.ti software generated two analytical networks as QSA, by using the codes based on the PESTEL model. The first analytical network generated was that of 'opportunities', and the second was that of 'threats' to biogas development in the region. The following section discusses these findings.

\section{Findings}

As biogas production remains poorly developed and established in the region studied, the findings were aimed at identifying the views of stakeholders on the external opportunities and threats that the biogas industry faces in the region. The categories of PESTEL were divided into external original elements, which could be attributed to the environment, in terms of opportunities and threats related to Project $X$. The first external element was coded in the subcategory 'opportunities', where the views of stakeholders on the various contributions of biogas to sustainability, as well as the conditions favorable for biogas development were assembled. The second external element was categorized as 'threats' and included aspects that are hard to overcome at the regional level for the successful development of biogas. Using QSA through a TNA was intended to identify the PESTEL factors that contributed to the manageable challenges that could potentiate biogas development in the region.

Figure 1 showing TNA (opportunities) and Figure 2 showing TNA (threats) depict parts of the thematic networks, with a few examples of the themes, that were created and generated by the use of the ATLAS.ti software. Thematic network analysis with ATLAS.ti is a creative and innovative way to identify and organize themes that answer the research questions of a study. The network feature in ATLAS.ti enables researchers to not only focus on themes, but also to identify the respective stakeholders to whom the themes matter most. With the use of different built-in features in ATLAS.ti, one can undertake further, detailed queries on the narratives of the stakeholders, regarding different issues and concerns identified in the SA. In this paper, only parts of the thematic analysis are presented in these figures, as the whole network had many themes, sources, codes and linkages, which would have rendered the text too small and illegible had it been presented. Some 
parts (for example, the literature review of journal articles and individual questionnaires) remain illegible, as these are generated by ATLAS.ti and the images presented herein cannot be enlarged. As these parts are not so important (they are shown as examples), a simplified version of the TNA used in the QSA by using the ATLAS.ti software is presented in Figures 1 and 2. These themes are presented as boxes with text starting with hexagonal symbols. In the ATLAS.ti software, a click on the boxes shows detailed information and descriptions for the respective themes and enables the generation of further results. The black lines show the relationship between the different themes (as well as between levels of themes), and the blue dotted lines show the respective sources of the data for the themes (for example, during focus group discussions, surveys, literature reviews).

After depicting each of the thematic networks, a brief description of the main findings is provided. In addition, Table 1 presents a summary of the main themes that are discussed as key findings.

Table 1. Summary of main themes discussed as findings.

\begin{tabular}{|c|c|c|}
\hline PESTEL & Opportunities & Threats \\
\hline Political & $\begin{array}{ll}\text { - } & \text { Collaboration } \\
\text { - } & \text { Municipality-ownership } \\
& \text { Biogas in sustainability goals } \\
& \text { of the region }\end{array}$ & $\begin{array}{ll}\text { - } & \text { Political Ignorance } \\
\text { - } & \text { Inadequate support } \\
\text { - } & \text { Energy priority- } \\
& \text { increased competition }\end{array}$ \\
\hline Economic & $\begin{array}{l}\text { - } \\
\text { muncrease production in the } \\
\text { - } \quad \text { Exploit willingness to grow } \\
\text { - } \\
\text { Support Small- } \\
\text { scale production }\end{array}$ & $\begin{array}{l}\text { - High investment cost } \\
\text { - The feasibility of obtaining a } \\
\text { return-Insufficient or } \\
\text { undeveloped infrastructure }\end{array}$ \\
\hline Social & $\begin{array}{l}\text { - } \quad \text { Increased Employment } \\
\text { Development of } \\
\text { climate solutions } \\
\text { - Need for information } \\
\text { and education }\end{array}$ & $\begin{array}{l}\text { - } \quad \text { Social acceptance } \\
\text { - } \quad \text { Plants in the neighbourhood }\end{array}$ \\
\hline Technical & $\begin{array}{ll}\text { - } & \text { General technological } \\
\text { development } \\
\text { - } & \text { Regional potential } \\
\text { - } & \text { Access to raw materials }\end{array}$ & $\begin{array}{l}\text { - } \quad \text { Diversity of substrates } \\
\text { - Logistics and transportation }\end{array}$ \\
\hline Environmental & $\begin{array}{ll}\text { - } & \text { Rich access to } \\
\text { natural resources } \\
\text { - }\end{array}$ & - Quality of digestant \\
\hline Legal & $\begin{array}{ll}\text { - } & \text { Precursors } \\
\text { - } & \text { Changes in laws }\end{array}$ & $\begin{array}{l}\text { - Lengthy process in } \\
\text { legal decisions }\end{array}$ \\
\hline
\end{tabular}

\subsection{Opportunities}

Opportunities observe the external factors that affect project management. Such factors are essentially gathered from SA to develop external strategies in building the external positive output for the project. The following sub-section therefore presents the TNA, focusing on the opportunities as external factors in the QSA of Project X. Figure 1 depicts the opportunities in Project X, uncovered through the TNA that was carried out in ATLAS.ti. 

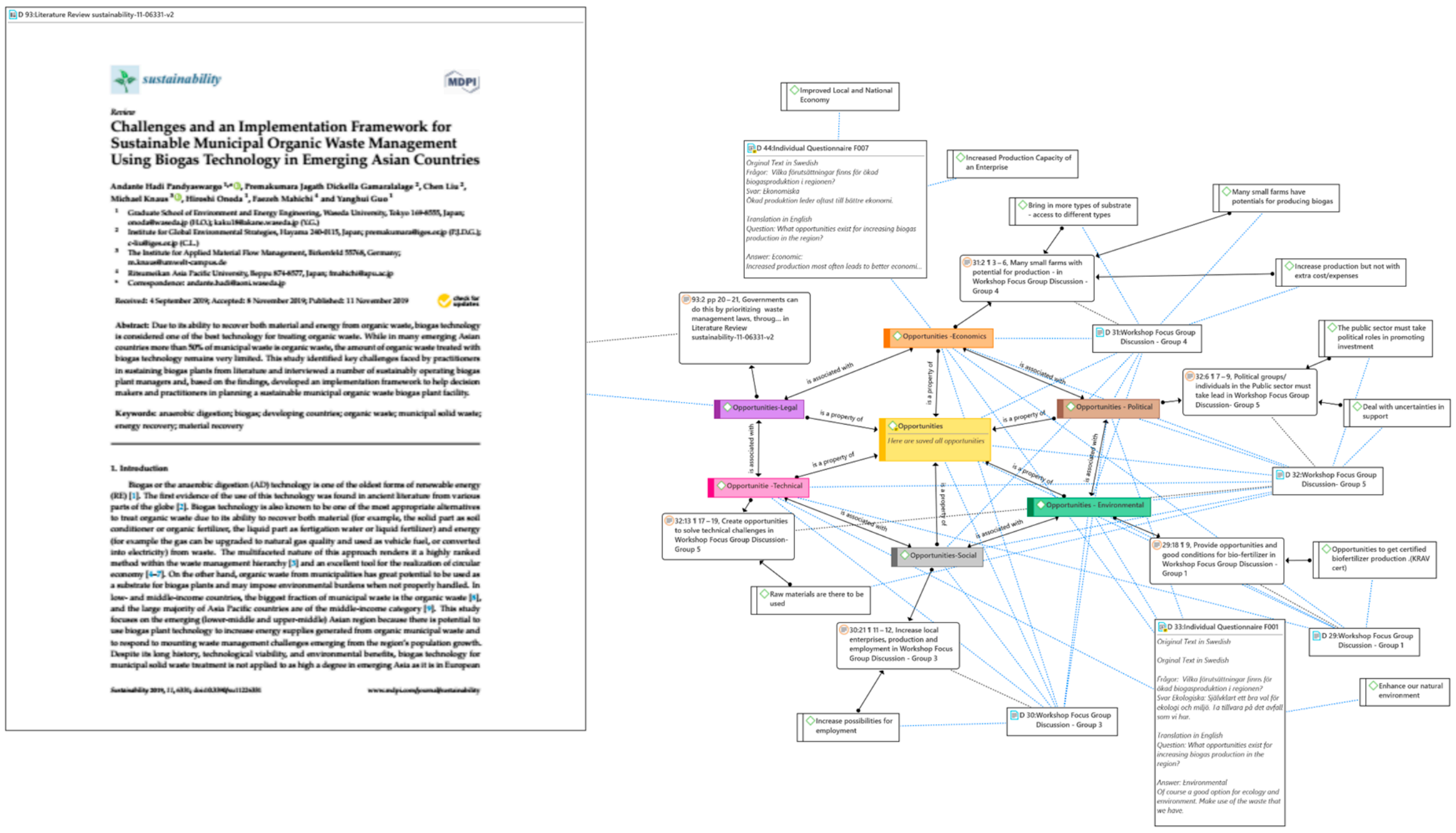

Figure 1. TNA—opportunities. 


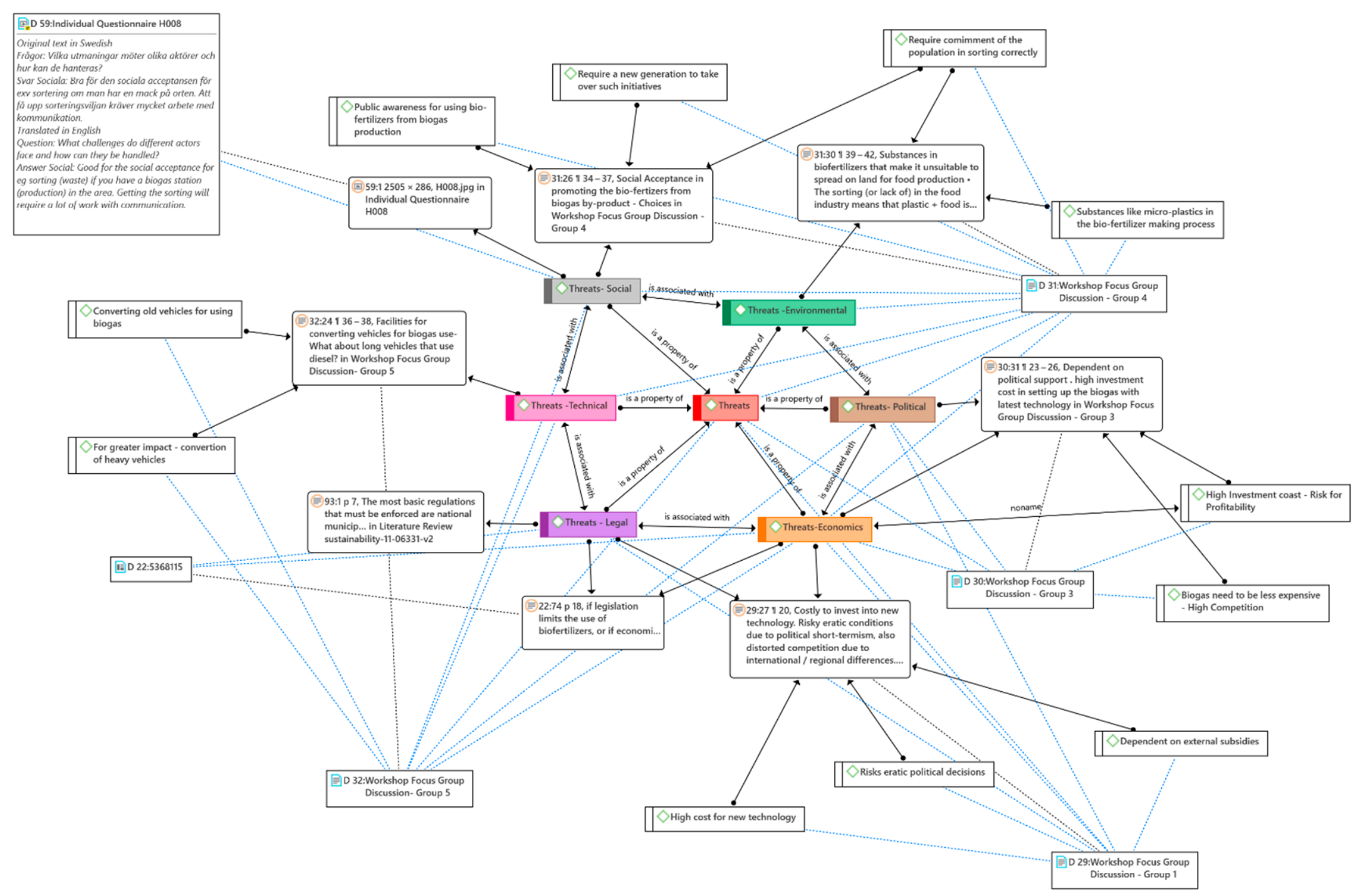

Figure 2. TNA-threats. 


\subsubsection{Political}

The QSA shows that political incentives have a major influence on biogas development. In Sweden, national policy incentives exist, which ranges from fiscal, economic to regulatory policy instruments $[57,58]$, which would favor the interests of different stakeholders in the biogas value chain. Rather than anticipating a specific effect from a certain policy, the instruments always act synergistically, with a combined effect on biogas development. However, the advantages of establishing a national biogas road map have not been clearly endorsed by stakeholders from the region. In particular, local stakeholders highlight three different main areas of development, which can contribute to opportunities for the local biogas industry: collaboration; municipally owned biogas plants; and the inclusion of biogas in the sustainability goals. There is a need for collaboration, which extends beyond the political boundaries, to coordinate forces directed at the regional development of biogas. Different parties have different goals and interests, which means that biogas is commonly ignored in political debates and proposals. One suggestion is that the municipality should take the lead by establishing more municipally owned biogas plants, which would increase the regional supply of biofuels. However, in order to succeed, biogas needs to be reexamined as an integral part of the local circular economy, which means that the promotion of biogas has to be clearly expressed in the sustainability goals of the local region.

\subsubsection{Economic}

The QSA shows that economic circumstances are the most important prerequisites for initiating small-scale biogas production in the region. Stakeholders highlight three different regional opportunities: to increase production in the municipally owned plants; exploit the willingness to grow; and support small-scale production. Some past initiatives have been taken to establish biogas companies that are municipally owned. Today, they face economic constraints, due to the low utilization of capacity, in part due to high requirement of capital and operational costs. This renders small regional companies passive at the moment in the business of biogas production. If conditions change, opportunities for growth could be exploited through an increase in production. This could contribute towards economic sustainability for the companies. There is also a willingness to grow among small and medium-sized companies, but these opportunities need strong support to be able to take the necessary steps towards developing biogas production.

\subsubsection{Social}

The analysis shows that biogas can contribute to social opportunities, i.e., the consequences of biogas establishment, which affect people in a positive way. Stakeholders highlight three main different areas with potential for development: an increase in employment rate; the development of climate-smart solutions; and the need for information and education. As biogas is a relatively new area of development, which requires the addition of new expertise both within biogas production and in the value chain, it creates the conditions for higher regional recruitment. Biogas also needs to be promoted as an excellent climate-smart solution. A prerequisite for achieving a higher employment rate is the creation of job opportunities, through an increase in information on the pros of biogas and establishing an impetus throughout the region.

\subsubsection{Technical}

The QSA shows that stakeholders perceive that the technical opportunities for biogas production are very stable. The analysis of the perceptions of technical solutions shows that the following three main opportunities are perceived to contribute to technical potential for regional biogas production: general technological development, regional potential and access to raw materials. The technological development of converting organic materials to biogas for energy purposes can be dated back to the 1970s in Sweden. Until now, this development has resulted in a large variety of technologies that can make use of feedstock of different origins to produce biogas, which can be used further for several 
energy applications (electricity, fuel and heat). This means that the regional conditions are sound for the application of the technology. Substrates within the region, such as separated organic waste, waste streams and byproducts from industries, agricultural and forestry residues can be utilized. There are ample raw materials (organic substrates) within the region; however, today they are not used efficiently. Technological development can perhaps enable the utilization of a larger repertoire of substrates.

\subsubsection{Environmental}

The QSA shows that stakeholders perceive the environmental opportunities as good, and they have several resource-based views, which are: rich access to natural resources, non-utilized resources and a win-win potential. The region has plentiful forest biomass and other organic substrates, which can be used for biogas production. The potential of these resources is great, which implies that they can contribute to create good biogas conditions for the region. If they were utilized, they would also contribute to the winwin effects, since the digestate (residues) from the biogas process can be recycled as bio-fertilizer on arable land. This not only closes the cycle of plant nutrients but leads also to the diminished use of mineral fertilizers, whose production and application lead to unsustainable environmental consequences.

\subsubsection{Legal}

The QSA shows that the legal consequences can be crucial for biogas production in the region. Precursors (other Swedish plants) have created opportunities through a change in the law, that allows the use of raw materials that promotes biogas production. For instance, a biogas producer has introduced a legislative amendment which allows for an increase in the use of offal, a change that regional companies could benefit from. Another change in the law is that the government allows the use of biogas in natural gas networks, which has the potential to expand the geographical scope of gas utilization.

\subsection{Threats}

Figure 2 shows TNA - generated with ATLAS.ti-and the threats identified from the QSA in Project X. Threats are the external factors that can act as obstacles in the project. In QSA, the stakeholders therefore had identified and discussed the threats mentioned below.

\subsubsection{Political}

The analysis of threats shows that stakeholders see three political challenges that can contribute to negative consequences for regional biogas development: political ignorance, inadequate support and energy priorities with increased competition. As a matter of fact, there is no consensus among the regional decision makers on making biogas an imperative on the way to achieving sustainable development. Moreover, political efforts have been made to support the development of different sustainable energy sources, such as biogas, biodiesel, hydrogen and electricity, which expose biogas to tough competition in a limited market. Having an awareness of the advantages of biogas influences the areas of energy that may be prioritized. It has a direct effect on increasing the competition among the types of energy to be promoted. This problem largely has to do with the national policymaking decisions on subsidies and financial support, which also affect regional biogas development, rendering the threats difficult to surmount.

\subsubsection{Economic}

The main threats identified by the stakeholders are high investment costs, weak infrastructure and establishment of gas stations. The biggest threat discussed was the high capital investment costs. Some stakeholders had made estimates, but their calculations displayed uncertain prospects for profit. In addition, as previously reported in the literature $[10,44,45]$, insufficient or undeveloped infrastructure is regarded as a barrier for the expansion of the biogas sector, even in this region. Among other things, they pointed to 
shortcomings in terms of few fueling stations where customers could easily refuel with biogas. This rendered the stakeholders, particularly the private companies on the demand side of the biogas value chain, reluctant to invest in biogas-fueled vehicles.

\subsubsection{Social}

The threats highlighted by stakeholders are mainly directed at two areas: social acceptance and biogas plants as a neighbor. Both threats are related and have to do with the smell that can be associated with biogas production. Biogas production can cause odors that spread to the geographically close vicinity and affect those who live next door to the plants. However, most biogas plants are not built close to residential areas, and the residual waste can be spread as fertilizer on fields. Furthermore, the input organic waste remains on the premises of the biogas plant, which does not contribute to odor problems for neighbors. Biogas production needs to have social acceptance, which can be difficult to accomplish without proper public instruction, education and communication.

\subsubsection{Technical}

Threats to this development mainly relate to the diversity of substrates, logistics and transport. Different substrates, due to their inherent properties, may need to be combined in specific ways, and sometimes pre-treated prior to digestion. In addition, the logistics and transport between the location of substrates and biogas production sites need to be streamlined and efficient, so that they do not contribute negatively to other PESTEL factors, such as environment, economy and social factors. These two threats to biogas development require technical adaptation and coordination. There is also a lack of technical competence and capacity in the region to promote investment in the biogas sector.

\subsubsection{Environmental}

Environmental threats are potentially associated with the quality of the digestate. These require extra processing to eliminate toxic or harmful substances and/or microorganisms that may remain. This processing has consequences for other PESTEL factors, such as the need for further technological development, poorer economy for the company and social consequences for people if the resulting bio-fertilizer is not safe to use.

\subsubsection{Legal}

Legal threats are perceived to be complex; for example, the long wait required for government decisions. It takes time and a lot of work to influence politicians before decisions are made. Knowledge, time and work are valuable assets that are limited in regional biogas stakeholders. Furthermore, legal issues require expert opinions and associated costs. This has consequences for other PESTEL factors, such as technical adjustment, financial investment costs and other restructuring costs.

\section{Discussion}

Generally, all stakeholders agree that biogas production in the region is conducive to the transition to a circular economy. In particular, the transition from fossil fuels to sources of renewable energy is urgently needed to mitigate climate change. As suggested in previous PESTEL studies, the benefit to the environment is always one of the most important driving forces for a transition to biofuels [49]. However, biogas does not only have a positive effect on the environment, but also on economic and social facets. In fact, the use of biogas from organic waste is a clear and dynamic example of a circular economy put into practice $[9,10,59]$. These returns are often found at several segments of society along the production and consumption circle, rather than only when biogas is used. For instance, household waste, which otherwise may cause environmental and health issues in the neighborhood, are managed and transformed into commercial products. Through the biogas process, high quality bio-fertilizer is generated that can replace chemical fertilizers that are used in farming, which contain mineral phosphate of fossil origin, a diminishing 
natural resource $[12,60]$. The transition into biogas establishment will promote an environmental awareness among citizens, thus inducing a change of attitudes and behavior. Moreover, the promotion of a renewable energy source for the transition to sustainable development indicates social responsibility [47]. Therefore, a biogas-related stakeholder plays a responsible role by demonstrating his/her commitment to sustainable solutions.

In general, energy policies should have a positive effect on the implementation of a certain renewable energy source for sustainable development [47]. However, in realizing their importance, such a realization must be accompanied with clear political objectives and prioritization at the local level; unclear political direction with ambiguous prioritization in this region will adversely affect biogas development. One of the biggest threats was found to be the high capital investment costs, and the feasibility of obtaining a return on investment for biogas production. This has also been described previously, where the implementation of energy efficient measures was often associated with high economic risk due to high initial investment costs $[44,47,61,62]$.

During the project, lack of technical competence in areas with a direct bearing on biogas development was identified as a challenge for successful regional biogas development at the local level. With an increase in regional biogas development, new job opportunities can arise, in particular for workers with the necessary competence and skills. A dynamic regional development would also lead to a higher overall employment rate. In this sense, one of the challenges ahead for Project $X$ is to create awareness and social acceptance of biogas development in the region. Knowledge and social acceptance strategies need to be based mainly on environmental and health concerns, related to climate urgency in the global society [63].

The QSA through the TNA demonstrates that even if there are advantages in and opportunities for promoting regional biogas production, a systematic change through several aspects of PESTEL is necessary to overcome the inherent threats to this development. To that end, the creation of a collaborative network of stakeholders was considered necessary for the sustainability of the project. It consisted of all those participating in and bearing an influence on regional 'biogas circles'; a platform through which regional stakeholders could communicate and interact with each other. The engagement of stakeholders is a strategic approach to increase sustainability of projects [5]. Project $X$ aimed at developing a knowledge base that could pave the way for large scale, follow-up projects, which would identify and implement measures for activating local entrepreneurs and other stakeholders. As the local communities in the region are tightly knit and local entrepreneurs are dependent on others in the value chain, this transition could only be brought about by engaging a larger group of stakeholders than the immediate target group, i.e., small entrepreneurs, in particular those with an interest in biogas development. In a similar manner, it has been argued that stakeholders' knowledge of the biogas value chain is crucial in the future development strategy of the sector [8].

In this sense, the QSA using a TNA with the help of the ATLAS.ti software was found to be instrumental in exploring and identifying opportunities and threats within the development of the biogas sector in the region for the following reasons. Firstly, such an approach allowed the project team to focus on the main themes regarding the potential and challenges, rather than on the stakeholders. By focusing on the themes, the project team could develop strategies to exploit the identified potential and find possible solutions for addressing the threats. Secondly, this particular approach enabled the project team to gain a better understanding of the complexities surrounding various themes. A sound understanding of the complex network of the themes is essential in sustainable project management, and ATLAS.ti facilitates the creation of a thematic network through a more integrated visualization. Through the TNA, sources of influence or concerns raised by stakeholders were easily identified through the exploration of the linkages. Thirdly, the QSA using TNA with the help of ATLAS.ti also created the opportunity for the project team to link the themes raised and discussed by the stakeholders in previous scientific studies, media reports and legal documents. For instance, such linkages facilitated the 
project team to better understand the causes of the identified threats and possibilities for solutions. Finally, by using ATLAS.ti, the project team could import data in different formats and sources, such as text from literature reviews and field notes, images from field visits and reports, audio/video recording from different social media, as well as geo-data, i.e., information based on geo-locations (for instance, from different business companies found in different municipal areas). ATLAS.ti also allowed the import and export of data from and to software for quantitative data analysis.

However, there are several challenges that one needs to consider in QSA when using TNA with ATLAS.ti. First and foremost, a profound knowledge of the ATLAS.ti software is essential, so that users can create and use networks of themes through coding and the creation of linkages. In this connection, one can access training sessions and materials, such as manuals and guides from the ATLAS.ti websites (ATLAS.ti.com, accessed on 20 May 2019). Secondly, the networks of themes can become big and complex, with various sources of data and information. In this sense, it is better to develop a small network of themes, depending on issues/problems/aspects that need to be focused on in project management. For instance, in this project, the team members decided to focus on potentials and threats. Thus, it was easy to work and generate information by creating/having two different networks, rather than a single big network. Finally, the main challenge is what to do with the data gathered and generated from the QSA by using TNA with ATLAS.ti. The results of the analysis on their own are not enough for the sustainability of a project. Project team members therefore need to design the strategic use of the findings and presentation from this SA approach. For instance, the findings from such an approach can facilitate collaborative networking in designing strategic plans.

\section{Implications, Limitations and Conclusions}

For Project X, the findings from the QSA highlight several opportunities as presented in the findings section of this article. However, the findings section also presents certain threats discussed by the stakeholders that needed to be seriously considered by the project team in developing strategies for sustainable project management. During Project $X$, it became apparent that the societal context was another critical aspect for allowing local businesses to develop and flourish; their successful establishment depends on political willingness, awareness of available subsidies and an understanding of legal issues and bureaucratic obstacles.

To streamline the expansion of biogas production in the region, the PESTEL analysis contributed to showing that development is guided by mandatory and more voluntary commitments and support for actors interested in biogas production. In the present study, mandatory aspects were mainly considered to have had the greatest impact on regional biogas development. These are political, economic and legal (PEL) aspects of PESTEL, while social and ecological (SE) are the result of these efforts. Technical (T) were not discussed as a problem, since these resources were considered as being met.

Political aspects entailed a need for much stronger political support, and an agenda to find facilitating solutions. The analysis showed that there is competition between different energy sources, strengthened by the current political management of state and municipal subsidies. Biogas, as an energy source, has been ignored in the overall political debate and been given less attention and support than other energy sources.

Economic aspects for managing the risk of high investment costs can make it difficult for individual low-resource players to initiate biogas production. This is worsened by the current subsidy system, in which the state chooses to promote individual energy solutions. Instead of finding the most appropriate fossil-free energy solutions to ecological problems, the promotion of specific energy sources has been conducted at the expense of the development of others. Further noted is infrastructural uncertainty, low expected financial returns due to few buyers of biogas and low expansion of regional filling stations.

Legal requirements for biogas production has increased the complexity of its management and applications for financial subsidies. This has made it difficult for biogas 
stakeholders to manage the financial investment requirements, which has hampered the development of biogas production.

As mandatory commitments are difficult to influence, this study sought to identify opportunity solutions that were easier to influence, since they are based on voluntary effort. Above all, the need for enhanced collaboration was noted, where stakeholder organizations would come together to handle political, financial and legal requirements. Our conclusion is that collaboration in various ways to create biogas systems could facilitate the establishment of local biogas production units. A uniform and more massive impact from several stakeholders can help to identify and articulate formal and specific demands for political support and create a financial and legal platform of knowledge. As more people become involved, the greater the effect. In the long run, this collaboration can utilize social skills, improve the environment, foster technical stakeholder knowledge and, thereby, create impetus to biogas production.

Two research implications have been noted, which have also contributed to some limitations. Firstly, the analysis was based on data from many different actors with a varying background and knowledge, which meant that the results may have been affected by how well the respondents were familiar with the biogas situation. Despite this, it was noted that there was good agreement among them, in how they perceived the situation; therefore, we consider the analysis to be reliable and representative of the region studied. The results can therefore contribute experience to regions that are at the same stage of development as the one studied. Secondly, the use of the PESTEL model entailed certain research implications, since several aspects are integrated into each other. For example, collaboration, is a social phenomenon that also affects the other PESTEL aspects. Political aspects have a bearing on the economic facets. The application of 'completed models' can mean that there is a risk of omitting factors that are important for the analysis.

The opportunity solutions mentioned above will be studied in-depth in the large-scale follow-up project discussed below. As biogas production can be small- to large-scale, we propose that more research effort is aimed at understanding how collaboration between different regional actors can contribute to the development of biogas systems of different scales. Project $X$ demonstrated that while some of the threats stem from specific conditions in the Swedish subsidy system, which, for example, allow for the unjust competition from neighboring countries, most threats and opportunities are commonplace in local biogas initiatives. In fact, there is a sense of having to 'reinvent the wheel' in each local initiative and a sense of urgency among stakeholders to learn from each other, in order to save time and money. No national body exists where all of this information can be found and coordinated. Project $X$ identified many of the same obstacles that have been previously reported, as reviewed by Karlsson [64]. The future question will be how to handle them in light of possible opportunities, in order to allow the development of more long term, successful business models.

The potential threats and opportunities that were identified in Project $X$ have formed the foundation for a large-scale follow-up project, in which the direction will be based on the conclusions drawn from Project X. The new project will focus on the integration and implementation of the four sustainability aspects (social, economic, technical and environmental) in the companies that make the primary target group of the project. The present situation is now being mapped and analyzed, and areas of improvement are being identified. The social aspects of the companies involved will also be examined, i.e., how they handle social aspects in their respective organizations. The effects of a circular economy on the organization of these companies will also be examined, for example, to what extent persons from other countries are being employed. GAP analysis will be conducted for all four sustainability aspects in the companies, with the goal of capability enhancement and increased awareness at both the individual and collective level. The new project will also study neighboring regions, which are currently one step ahead in biogas plant establishment. This will be completed in order to examine the challenges and opportunities in their respective biogas development, and to identify the methods by 
which they have implemented and actively promoted the establishment of local biogas plants and created awareness in the population. In addition, the new project will study specific cases (companies), so-called 'role models', located in other parts of Sweden, in which small entrepreneurs have initiated joint biogas production plants with successful track records. The role models will serve as sources of inspiration, information and contact points for the extension of the local networks in the region studied in the new project.

Author Contributions: Conceptualization, K.R.; methodology, K.R. and A.S.; software, K.R.; validation, A.S., Z.W. and S.A.I.W.; formal analysis, K.R. and A.S.; investigation, K.R., A.S., Z.W. and S.A.I.W.; resources, K.R., A.S., Z.W. and S.A.I.W.; writing-original draft preparation, K.R. and A.S.; writing-review and editing, Z.W. and S.A.I.W.; visualization, K.R.; supervision, K.R. and A.S.; project administration, Z.W. and S.A.I.W. All authors have read and agreed to the published version of the manuscript.

Funding: This work was supported financially by Region Gävleborg [Grant numbers 00209801 and 20203771], the University of Gävle and the European Regional Development Fund of the European Union [Grant number 20204053].

Institutional Review Board Statement: Ethical review and approval were waived for this study. According to the Swedish law on social research ethics [65], (para 460), social research that does not involve any records of names or any details that could connect a specific person to a crime or illegal activity do not need to have ethical approval from a board.

Informed Consent Statement: Informed consent was obtained from the participants prior to data collection.

Data Availability Statement: Anonymized data can be requested from the research team.

Acknowledgments: The authors would like to thank all the participating stakeholders in this project.

Conflicts of Interest: The authors declare no known competing financial interests or personal relationships that could have influenced the work.

\section{References}

1. Whyte, P.; Lamberton, G. Conceptualising sustainability using a cognitive mapping method. Sustainability $2020,12,1977$. [CrossRef]

2. Elkington, J. Cannibals with Forks: The Triple Bottom Line of 21st Century Business; Capstone: Oxford, UK, 1997; ISBN 1-900961-27-X.

3. Dangelico, R.M.; Nonino, F. Sustainable Project Management: A Conceptualization-Oriented Review and a Framework Proposal for Future Studies. Sustainability 2019, 11, 1-16.

4. Gilbert Silvius, A.J.; Schipper, R. Exploring the relationship between sustainability and project success-Conceptual model and expected relationships. Int. J. Inf. Syst. Proj. Manag. 2016, 4, 5-22.

5. Kuchta, D.; Mrzygłocka-Chojnacka, J. An approach to increase the sustainability of projects and their outcomes in public sector through improving project definition. Sustainability 2020, 12, 4804. [CrossRef]

6. Toljaga-Nikolić, D.; Todorović, M.; Dobrota, M.; Obradović, T.; Obradović, V. Project management and sustainability: Playing trick or treat with the planet. Sustainability 2020, 12, 8619. [CrossRef]

7. Lyon, C.; Cordell, D.; Jacobs, B.; Martin-Ortega, J.; Marshall, R.; Camargo-Valero, M.A.; Sherry, E. Five pillars for stakeholder analyses in sustainability transformations: The global case of phosphorus. Environ. Sci. Policy 2020, 107, 80-89. [CrossRef] [PubMed]

8. Arfan, M.; Wang, Z.; Soam, S.; Eriksson, O. Biogas as a Transport Fuel-A System Analysis of Value Chain Development in a Swedish Context. Sustainability 2021, 13, 4560. [CrossRef]

9. Ahlberg-Eliasson, K.; Nadeau, E.; Levén, L.; Schnürer, A. Production efficiency of Swedish farm-scale biogas plants. Biomass Bioenergy 2017, 97, 27-37. [CrossRef]

10. Ammenberg, J.; Anderberg, S.; Lönnqvist, T.; Grönkvist, S.; Sandberg, T. Biogas in the transport sector-actor and policy analysis focusing on the demand side in the Stockholm region. Resour. Conserv. Recycl. 2018, 129, 70-80. [CrossRef]

11. Ammenberg, J.; Dahlgren, S. Sustainability Assessment of Public Transport, Part I-A Multi-Criteria Assessment Method to Compare Different Bus Technologies. Sustainability 2021, 13, 825. [CrossRef]

12. Cong, R.G.; Caro, D.; Thomsen, M. Is it beneficial to use biogas in the Danish transport sector?-An environmental-economic analysis. J. Clean. Prod. 2017, 165, 1025-1035. [CrossRef]

13. Karlsson, N.P.E.E.; Hoveskog, M.; Halila, F.; Mattsson, M. Early phases of the business model innovation process for sustainability: Addressing the status quo of a Swedish biogas-producing farm cooperative. J. Clean. Prod. 2016, 172, 2759-2772. [CrossRef] 
14. Karlsson, N.P.E.E.; Hoveskog, M.; Halila, F.; Mattsson, M. Business modelling in farm-based biogas production: Towards network-level business models and stakeholder business cases for sustainability. Sustain. Sci. 2019, 14, 1071-1090. [CrossRef]

15. Varvasovszky, Z.; Brugha, R. A stakeholder analysis. Health Policy Plan. 2016, 24, 96-99. [CrossRef]

16. Henriksen, L.F. The global network of biofuel sustainability standards-setters. Env. Polit. 2015, 24, 115-137. [CrossRef]

17. Froehlich, D.E.; Van Waes, S.; Schäfer, H. Linking Quantitative and Qualitative Network Approaches: A Review of Mixed Methods Social Network Analysis in Education Research. Rev. Res. Educ. 2020, 44, 244-268. [CrossRef]

18. Bracke, M.B.M.; de Greef, K.H.; Hopster, H. Qualitative stakeholder analysis for the development of sustainable monitoring systems for farm animal welfare. J. Agric. Environ. Ethics 2005, 18, 27-56. [CrossRef]

19. Severin, A.; Chataway, J. Purposes of peer review: A qualitative study of stakeholder expectations and perceptions. Learn. Publ. 2021, 34, 144-155. [CrossRef]

20. Hwang, S. Utilizing qualitative data analysis software: A review of Atlas.ti. Soc. Sci. Comput. Rev. 2008, 26, 519-527. [CrossRef]

21. Danso, A.; Adomako, S.; Lartey, T.; Amankwah-Amoah, J.; Owusu-Yirenkyi, D. Stakeholder integration, environmental sustainability orientation and financial performance. J. Bus. Res. 2020, 119, 652-662. [CrossRef]

22. Sundström, A. Globalisation, CSR and Business Legitimacy in Local Relationships; Swedish University of Agricultural Sciences: Uppsala, Sweden, 2009; ISBN 978-91-86195-70-0.

23. Freeman, R.E. Strategic Management: A Stakeholder Approach; Pitman: Cambridge, MA, USA, 1984; ISBN 9781405164023.

24. Mitchell, R.K.; Agle, B.R.; Wood, D.J. Toward a theory of stakeholder identification and salience: Defining the principle of who and what really counts. Acad. Manag. Rev. 1997, 22, 853-886. [CrossRef]

25. Miles, S. Stakeholder Theory Classification: A Theoretical and Empirical Evaluation of Definitions. J. Bus. Ethics 2017, 142, 437-459. [CrossRef]

26. Freeman, R.E.; Harrison, J.; Wicks, A.C.; Parmar, B.; de Colle, S. Stakeholder Theory: The State of the Art; Cambridge University Press: New York, NY, USA, 2010; ISBN 978-0-521-19081-7.

27. Hörisch, J.; Freeman, R.E.; Schaltegger, S. Applying Stakeholder Theory in Sustainability Management: Links, Similarities, Dissimilarities, and a Conceptual Framework. Organ. Environ. 2014, 27, 328-346. [CrossRef]

28. Barnard, C.I. The Functions of the Executive; Harvard University Press: Cambridge, MA, USA, 1938; ISBN 0674328000.

29. Rhenman, E.; Stymne, B. Företagsledning I en förändelig värld; Aldus/Bonniers: Stockholm, Sweden, 1965; ISBN 951-96013-6-8.

30. Freeman, R.E.; Phillips, R.; Sisodia, R. Tensions in Stakeholder Theory. Bus. Soc. 2020, 59, 213-231. [CrossRef]

31. Eskerod, P.; Huemann, M. Sustainable development and project stakeholder management: What standards say. Int. J. Manag. Proj. Bus. 2013, 6, 36-50. [CrossRef]

32. Laplume, A.O.; Sonpar, K.; Litz, R.A. Stakeholder theory: Reviewing a theory that moves us. J. Manag. 2008, 34, 1152-1189. [CrossRef]

33. Reed, M.S.; Graves, A.; Dandy, N.; Posthumus, H.; Hubacek, K.; Morris, J.; Prell, C.; Quinn, C.H.; Stringer, L.C. Who's in and why? A typology of stakeholder analysis methods for natural resource management. J. Environ. Manag. 2009, 90, 1933-1949. [CrossRef] [PubMed]

34. Colvin, R.M.; Witt, G.B.; Lacey, J. Power, perspective, and privilege: The challenge of translating stakeholder theory from business management to environmental and natural resource management. J. Environ. Manag. 2020, 271, 110974. [CrossRef] [PubMed]

35. Steurer, R. Mapping stakeholder theory anew: From the "Stakeholder Theory of the Firm" to three perspectives on business-society relations. Bus. Strateg. Environ. 2006, 15, 55-69. [CrossRef]

36. Valentinov, V.; Roth, S.; Will, M.G. Stakeholder Theory: A Luhmannian Perspective. Adm. Soc. 2019, 51, 826-849. [CrossRef]

37. Uribe, D.F. What Is Going on with Stakeholder Theory in Project Management Literature? A Symbiotic Relationship for Sustainability. Sustainability 2018, 10, 1300. [CrossRef]

38. Valentinov, V.; Hajdu, A. Integrating instrumental and normative stakeholder theories: A systems theory approach. J. Organ. Chang. Manag. 2019. [CrossRef]

39. Gasparski, W.W. The stakeholder organisation theory and its systemic foundation. Int. J. Gen. Syst. 2009, 38, 659-665. [CrossRef]

40. Wu, W.; He, F.; Zhuang, T.; Yi, Y. Stakeholder Analysis and Social Network Analysis in the Decision-Making of Industrial Land Redevelopment in China: The Case of Shanghai. Int. J. Environ. Res. Public Health 2020, 17, 9206. [CrossRef] [PubMed]

41. Scott, J. Social Network Analysis, 4th ed.; SAGE Publications Ltd.: London, UK, 2017; ISBN 9781473952119.

42. Zhou, S.; Zhou, M.; Wang, Y.; Gao, Y.; Liu, Y.; Shi, C.; Lu, Y.; Zhou, T. Bibliometric and social network analysis of civil engineering sustainability research from 2015 to 2019. Sustainability 2020, 12, 6842. [CrossRef]

43. Luthe, T.; Wyss, R. Resilience to climate change in a cross-scale tourism governance context: A combined quantitative-qualitative network analysis. Ecol. Soc. 2016, 21, 27. [CrossRef]

44. Lönnqvist, T.; Anderberg, S.; Ammenberg, J.; Sandberg, T.; Grönkvist, S. Stimulating biogas in the transport sector in a Swedish region-An actor and policy analysis with supply side focus. Renew. Sustain. Energy Rev. 2019, 113, 109269. [CrossRef]

45. Mutter, A. Obduracy and Change in Urban Transport-Understanding Competition Between Sustainable Fuels in Swedish Municipalities. Sustainability 2019, 11, 6092. [CrossRef]

46. Yudha, S.W.; Tjahjono, B.; Kolios, A. A PESTLE policy mapping and stakeholder analysis of Indonesia's fossil fuel energy industry. Energies 2018, 11, 1-22.

47. Christodoulou, A.; Cullinane, K. Identifying the main opportunities and challenges from the implementation of a port energy management system: A SWOT/PESTLE analysis. Sustainability 2019, 11, 6046. [CrossRef] 
48. Yüksel, I. Developing a Multi-Criteria Decision Making Model for PESTEL Analysis. Int. J. Bus. Manag. 2012, 7, 52. [CrossRef]

49. Achinas, S.; Horjus, J.; Achinas, V.; Jan, G.; Euverink, W. A PESTLE Analysis of Biofuels Energy Industry in Europe. Sustainability 2019, 11, 5981. [CrossRef]

50. Boyatzis, R.E. Transforming Qualitative Information: Thematic Analysis and Code Development; Sage Publications: Thousand Oaks, CA, USA, 1998; ISBN 978-0-7619-0960-6.

51. Attride-Stirling, J. Thematic networks: An analytic tool for qualitative research. Qual. Res. 2001, 1, 385-405. [CrossRef]

52. Saldaña, J. The Coding Manual for Qualitative Researchers, 2nd ed.; SAGE Publications Ltd.: London, UK, 2013; pp. 61-86. ISBN 9781446247365.

53. Rambaree, K. Abductive thematic network analysis (ATNA) using ATLAS-ti. In Innovative Research Methodologies in Management: Volume I: Philosophy, Measurement and Modelling; Moutinho, L., Sokele, M., Eds.; Palgrave Macmillan: Cham, Switzerland, 2017; ISBN 9783319643946.

54. Braun, V.; Clarke, V. Using thematic analysis in psychology. Qual. Res. Psychol. 2006, 3, 77-101. [CrossRef]

55. Friese, S. Qualitative Data Analysis with ATLAS.ti, 3rd ed.; SAGE Publications Inc.: London, UK, 2019; ISBN 9781526458926.

56. Friese, S.; Susanne, F. ATLAS.ti 8 Windows User Manual; GmbH, ATLAS.ti Scientific Software Development: Berlin, Germany, 2020; ISBN 978-1-4799-1749-5.

57. Silver, C.; Lewins, A. Using Software in Qualitative Research: A Step-by-Step Guide, 1st ed.; SAGE Publications Ltd.: London, UK, 2014; ISBN 9781446249727.

58. Hellsmark, H.; Söderholm, P. Innovation policies for advanced biorefinery development: Key considerations and lessons from Sweden. Biofuels Bioprod. Biorefining 2017, 11, 28-40. [CrossRef]

59. Larsson, M.; Grönkvist, S.; Alvfors, P. Upgraded biogas for transport in Sweden-Effects of policy instruments on production, infrastructure deployment and vehicle sales. J. Clean. Prod. 2016, 112, 3774-3784. [CrossRef]

60. Corvellec, H. Sustainability objects as performative definitions of sustainability: The case of food-waste-based biogas and biofertilizers. J. Mater. Cult. 2016, 21, 383-401. [CrossRef]

61. Brunklaus, B.; Rex, E.; Carlsson, E.; Berlin, J. The future of Swedish food waste: An environmental assessment of existing and prospective valorization techniques. J. Clean. Prod. 2018, 202,1-10. [CrossRef]

62. Yousuf, A.; Khan, M.R.; Pirozzi, D.; Ab Wahid, Z. Financial sustainability of biogas technology: Barriers, opportunities, and solutions. Energy Sources Part B Econ. Plan. Policy 2016, 11, 841-848. [CrossRef]

63. Lönnqvist, T.; Grönkvist, S.; Sandberg, T. Forest-derived methane in the Swedish transport sector: A closing window? Energy Policy 2017, 105, 440-450. [CrossRef]

64. Karsson, N.P.E. Business models and business cases for financial sustainability: Insights on corporate sustainability in the Swedish farm-based biogas industry. Sustain. Prod. Consum. 2019, 18, 115-129. [CrossRef]

65. Svensk Författningssamling. 'Lagm Ändring i Lagen (2003:460) om Etikprövning av Forskning som Avser Människor'. 2018. Available online: https:/ / www.lagboken.se/views / pages / getfile.ashx?portalId=56anddocId=3472817andpropId=5 (accessed on 10 September 2020). 